() (1) https://creativecommons.org/licenses/by/4.0/

ARTIGO

\title{
POLÍTICAS EDUCACIONAIS DOS GOVERNOS PT (2003-2016): IMPACTO NO PERFIL DOS GRADUANDOS EM PSICOLOGIA
}

\author{
JOÃO PAULO MACEDO ${ }^{1 ; 2}$ \\ ORCID: https://orcid.org/0000-0003-4393-8501 \\ SARA TELES REIS \\ ORCID: https://orcid.org/0000-0003-0887-6317
}

\begin{abstract}
RESUMO: Objetivou-se analisar o impacto das políticas educacionais para o ensino superior ao longo dos Governos do Partido dos Trabalhadores/PT (2003-2016), quanto ao perfil dos estudantes de graduação de Psicologia no Brasil. Trata-se de um estudo documental, com base nos microdados do Censo do Ensino Superior e do Exame Nacional do Desempenho dos Estudantes, referente ao ciclo de 2015, divulgado em domínio público pelo Ministério da Educação. Foram selecionados estudantes de Instituições de Ensino Superior públicas e privadas para compor a amostra final de 18.788 estudantes. A análise foi realizada por meio do Software Statistical Package for the Social Sciences (SPSS), versão 21, com base no teste quiquadrado $(\chi 2)$ de independência e grau de significância $0,05(\mathrm{p}<0,05)$. Observouse o acesso de um novo perfil de alunos oriundos de famílias com renda mais baixa; com mães e pais com menor escolaridade; procedentes de escolas públicas; sendo os primeiros da família a cursarem um curso de nível superior. Nesta lógica, é possível entender a importância do Prouni, Fies e Reuni tanto quanto a ampliação do acesso como quanto a uma certa deselitização do perfil do estudante de Psicologia no Brasil. Entende-se que tal mudança tenha se dado pelo impulsionamento das políticas de ampliação do acesso ao ensino superior, notadamente voltadas para o setor privado (Fies e Prouni).
\end{abstract}

Palavras-chave: Reuni, Prouni, Fies, deselitização, formação em Psicologia.

\section{EDUCATIONAL POLICIES OF THE PT GOVERNMENTS AND THE IMPACT ON THE PROFILE OF UNDERGRADUATES IN PSYCHOLOGY}

\begin{abstract}
The objective of this article was to analyze the impact of educational policies for higher education during the Workers' Party/PT governments (2003-2016), regarding the profile of Psychology undergraduate students in Brazil. This is a documental study, based on microdata from the Census of Higher Education and the National Examination of Student Performance, referring to the 2015 cycle, released in the public domain by the Ministry of Education. Students from public and private Higher Education Institutions were selected to compose the final sample of 18,788 students. The analysis was performed using the Statistical Package for the Social Sciences (SPSS) software, version 21, based on the chi-square test $(\chi 2)$ of independence and 0.05 significance level $(p<0.05)$. It was observed the access of a new profile of students coming from families with lower income; with mothers and fathers with less education; coming from public schools; being the first in the family to attend an undergraduate course.
\end{abstract}

\footnotetext{
${ }^{1}$ Docente dos Programas de Pós-Graduação em Psicologia da Universidade Federal do Delta do Parnaíba (UFDPar), Parnaíba, PI, Brasil.

${ }^{2}$ Universidade Federal do Ceará (UFC). Bolstia Produtividade do CNPQ. Fortaleza, CE, Brasil. <jpmacedo@ufpi.edu.brr>

${ }^{3}$ Psicóloga pela Universidade Federal do Delta do Parnaíba (UFPI). Parnaíba, PI, Brasil. <sarateles10@gmail.com> 
In this logic, it is possible to understand the importance of Prouni, Fies and Reuni both in terms of widening access and in terms of a certain de-elitization of the profile of Psychology students in Brazil. It is noteworthy that such a change has been brought about by the boosting of policies to expand access to higher education, especially those aimed at the private sector (Fies and Prouni).

Keywords: Reuni, Prouni, Fies, non-elitization, training in psychology.

\section{LAS POLÍTICAS EDUCATIVAS DE LOS GOBIERNOS DE LOS PT Y EL IMPACTO EN EL PERFIL DE LOS ESTUDIANTES UNIVERSITARIOS DE PSICOLOGÍA}

RESÚMEN: El objetivo fue analizar el impacto de las políticas educativas para la educación superior, a lo largo de los gobiernos del Partido de los Trabajadores/PT (2003-2016), respecto al perfil de los estudiantes de pregrado de Psicología en Brasil. Se trata de un estudio documental, basado en los microdatos del Censo de Educación Superior y del Examen Nacional de Rendimiento Estudiantil, correspondientes al ciclo 2015, liberados en el dominio público por el Ministerio de Educación. Se seleccionaron estudiantes de instituciones de educación superior públicas y privadas para componer la muestra final de 18.788 estudiantes. El análisis se realizó con el programa informático Statistical Package for the Social Sciences (SPSS), versión 21, basado en la prueba de chi-cuadrado $(\chi 2)$ de independencia y un nivel de significación de $0,05(\mathrm{p}<0,05)$. Se observó el acceso de un nuevo perfil de estudiantes provenientes de familias con menores ingresos; con madres y padres con menos educación; provenientes de escuelas públicas; siendo los primeros de la familia en cursar un curso de pregrado. En esta lógica, es posible entender la importancia de Prouni, Fies y Reuni tanto en términos de ampliación del acceso como en términos de una cierta deselitización del perfil del estudiante de Psicología en Brasil. Cabe destacar que este cambio se ha producido gracias al impulso de las políticas de ampliación del acceso a la educación superior, centradas especialmente en el sector privado (Fies y Prouni).

Palabras clave: Reuni, Prouni, Fies, noelitización, formación en psicología.

\section{INTRODUÇÃO}

Pensar acerca do impacto das políticas educacionais no perfil de estudantes de graduação de Psicologia, nos últimos anos, requer uma análise histórica do ensino superior no país. Sabemos que a desigualdade social em todas as suas facetas e moldes, principalmente no que se refere ao segmento educacional é produto do sistema capitalista. Em seu histórico, a educação brasileira é permeada de contradições por não ter nascido em bases de igualdade e acesso para todos. Para Saviani (1944), a educação atua como importante instrumento de reprodução das relações de produção, revelando seu caráter segregador e marginalizador. Sendo assim, nunca no país se pretendeu fazer da educação um modelo universal, tendo em vista sua função de reprodução das desigualdades sociais evidenciada pela própria natureza seletiva da escola brasileira (Saviani \& Duarte, 2012).

O capitalismo financeiro é quem rege a estrutura econômica do país, sendo este quem comanda as políticas de modo geral, inclusive as educacionais, com sua racionalidade neoliberal (Saviani, 1998). Nesse sentido, nota-se que os projetos e legislações atuais resultam de uma ideologia na qual a educação torna-se condição necessária para a reprodução econômica e ideológica do capital. Se por um lado, a bandeira da igualdade de oportunidades passa a se subordinar à lógica racional do mercado, por outro, as reformas no segmento educacional ficam reduzidas ao cumprimento de objetivos que atendem, prioritariamente, ao imperativo econômico, cujo papel estratégico dado à educação é de adaptar indivíduos ao mercado de trabalho, por meio do investimento no setor privado, instituindo uma lógica que favorece o fortalecimento do mercado (Cruz, 2003; Giron, 2014).

As políticas de educação refletem determinado projeto societário ou possíveis projetos coletivos em que os interesses defendidos estão ancorados em certa concepção de sujeito e construção 
de um modelo de sociedade (Giron, 2014). Para Netto (1999), os projetos societários disputam imagens da sociedade que se pretende edificar, a partir de um conjunto de valores que justificam sua construção e os meios (materiais e culturais) para realizá-lo: uns atendem aos interesses das classes trabalhadoras e subalternas, e outros da dominante. No caso de um projeto educacional referendado pela lógica capitalista, a concepção de sociedade que prevalece é aquela que preza pela competição, pela ética utilitarista, pela meritocracia neoliberal e pela exclusão (Giron, 2014). No caso do ensino superior, tais contradições aprofundam-se sinalizando a herança de um sistema, que no seu embrião, já era permeado por prestígios sociais e lógicas que davam sustentação às classes dominantes (Cavalcante, 2000).

Nesse sentido, as políticas educacionais no Brasil, em seu processo histórico, foram implantadas por lógicas e intencionalidades voltadas para adaptações a modelos (neo)liberais e reprodução dos modos de vida da sociedade (Giron, 2008). Para pensá-las, requer rever o momento histórico e a conjuntura política em que foram implantadas, avaliando as necessidades do modelo social e econômico vigente.

Considerando que a educação no Brasil passou por significativas reformas e transformações de modo a acompanhar as dinâmicas sociais, políticas e econômicas do país, nos deteremos no presente estudo sob as políticas do ensino superior ao longo do período dos Governos do Partido dos Trabalhadores (PT) no plano federal. Pressupõe-se que tais políticas resultaram em mudanças significativas quanto ao padrão do perfil dos alunos, uma vez que possibilitou maior acesso ao ensino superior.

Em 2003, com a entrada do Governo do Partido dos Trabalhadores na Presidência da República, o país passou a viver um importante momento histórico de ampliação do acesso ao ensino superior pela expansão e investimento financeiro das políticas públicas educacionais, por meio do: Programa Universidade para Todos (PROUNI) e Programa de Apoio a Planos de Reestruturação e Expansão das Universidades Federais (REUNI), implementados durante os governos Luís Inácio Lula da Silva (2003-2010) e Dilma Vana Rousseff (2011-2016); além do aperfeiçoamento do Fundo de Financiamento ao Estudante do Ensino Superior (FIES), criado no Governo Fernando Henrique Cardoso (FHC), contudo, ampliado nos governos do Partido dos Trabalhadores (PT) (Silva \& Castro, 2014).

Dentre estas políticas, o FIES foi o primeiro a ser criado, em 1999, e regulamentado pela Lei $\mathrm{n}^{\circ} .10 .260 / 2001$, com o objetivo de financiar parte ou todo o valor da mensalidade de estudantes de baixa renda, regularmente matriculados em cursos superiores em IES privadas. Para Aprile e Barone (2018), o FIES é um programa destinado a financiar a graduação no ensino superior de estudantes que não têm condições de arcar integralmente com os custos de sua formação, regularmente matriculados em instituições privadas cadastradas no Programa, e com avaliação positiva nos processos conduzidos pelo MEC. Foi concebido com o propósito de ser um programa autossustentado, em termos financeiros, para que substituisse o Programa de Crédito Educativo (PCE/CREDUC).

Inicialmente o FIES cobria até $70 \%$ do valor da mensalidade cobrado pela instituição de ensino. A partir de setembro de 2005 passou a financiar 50\% do valor da mensalidade, e posteriormente 100\%, com a publicação da Lei n. ${ }^{\circ}$ 11.552/2007 (Oliveira \& Carnielli, 2010). Tais alterações buscaram ampliar o número de alunos atendidos, sendo registrados 449.786 mil estudantes beneficiados em 2006. Em 2016 houve 325 mil inscrições no programa, sendo que, por parte das instituições de ensino, participaram 1.110 instituições mantenedoras, 1.513 IES, 2.059 campi e 23.035 cursos/habilitações (Aprile \& Barone, 2018).

Quanto ao Programa Universidade para Todos, este foi criado pela Lei n. ${ }^{\circ}$ 11.096/2005 e implementado no mesmo ano com a finalidade de criar condições de acesso em IES privadas para estudantes oriundos, em sua maioria, das camadas populares ou de estratos da classe média que não dispunham de recursos para assumir os custos de uma formação superior em instituições privadas. Ocorre por meio de bolsas de estudo de diferentes modalidades:

bolsa de estudo integral concedida a brasileiros não portadores de diploma de curso superior, cuja renda per capita não exceda o valor de até um salário mínimo e meio; e bolsa de estudo parcial $(50 \%)$ concedida a brasileiros não portadores de diploma de curso superior, cuja renda familiar per capita não exceda o valor de até três salários mínimos (Aprile \& Baroni, 2018, p. 49). 
De acordo com as autoras, Fies e Prouni são políticas educacionais voltadas para a população de baixa renda e de camadas populares, o que inclui alunos oriundos de escolas públicas. São políticas inclusivas de caráter compensatórias, focalizadas e afirmativas. Compensatórias porque viabilizam auxílio tanto para as IES quanto para os alunos, focalizadas por serem direcionadas para públicos de certo perfil social e econômico, e afirmativas porque garantem a participação de pessoas que sofreram discrimição, de classe e/ou étnico-racial, dentre outras, para a manutenção do seu processo formativo, no tocante ao custeio das mensalidades (Aprile \& Baroni, 2018).

Porém, Catani et al. (2006) sugerem que, apesar dos avanços com a "reforma universitária" realizada pelo Partido dos Trabalhadores, a exemplo do Prouni enquanto política pública de acesso à educação superior, não houve qualquer estratégia voltada para a garantia da permanência do estudante, elemento fundamental para a democratização do ensino superior. Além disso, é preciso considerar a qualidade das instituições e cursos em que o acesso para estudantes de camadas populares foi ampliado, tendo em vista que as avaliações dos cursos em instituições privadas, em grande parte composto por faculdades isoladas, têm apresentado desempenho ruim na nota do ENADE.

Como é possível perceber, ambos os programas voltam-se para a expansão do setor privado de educação superior no país, apontando para uma privatização do ensino ao colocar o fundo público da educação à disposição do setor privado, a partir de políticas neoliberais, favorecendo, com isso, o aquecimento do mercado com a financeirização da educação superior (Giron, 2008).

Face ao cenário do setor privado no ensino superior e a lógica da privatização, de acordo com Galzerano e Minto (2019), vivenciamos a fase contemporânea da acumulação do capital, por meio do capital fictício, caracterizada pela financeirização da educação, a partir da oligopolização e da transnacionalização de empresas multinacionais voltadas para o ensino superior no país. Essa forma de acumulação se dá, sobretudo, pelo desenvolvimento do sistema de crédito, que permite ao capital se acumular como capital-dinheiro revelando-se cada vez mais 'irreal', eis o motivo da classificação "capital fictício" (Dominczak, 2015).

Desta maneira, os programas financiados pelo fundo público da educação, apoiado pelo Estado brasileiro, como Fies, Prouni, o Programa Nacional de Acesso ao Ensino Técnico e Emprego (Pronatec) e o Programa Nacional do Livro e do Material Didático (PNLD), são definidos, por Galzerano e Minto (2019), como mecanismos essenciais para a garantia da rentabilidade das empresas privadas e de seus acionistas no mercado financeiro. Os mesmos autores referem que o processo de financeirização é um mecanismo em que o retorno do capital não acontece mais pela produção, mas pelo capital retido através de empréstimos, como no caso do Fies que funcionava como uma maneira de "trocar" o pagamento regular das mensalidades pelo financiamento a baixo custo proposto pelo Programa, em evidente benefício das empresas de educação, representando, assim, um desenvolvimento da lógica da acumulação capitalista contemporânea no setor educacional brasileiro (Galzerano \& Minto, 2018, 2019). Nesse aspecto, a educação se torna mercadoria e como resultado emerge uma "dupla sobreposição do interesse privado sobre a educação: as empresas educacionais possuem, em suas atividades, um meio para a obtenção de lucros; e seus investidores do setor financeiro, também" (Galzerano \& Minto, 2019, p. 11).

Além disso, Almeida et al. (2012), ao analisarem o processo de democratização do acesso e a taxa do ensino superior na realidade brasileira e portuguesa, sinalizam que no Brasil, a expansão no ensino superior foi feita essencialmente às custas de um aumento exponencial de instituições do setor privado, também ampliado pela multiplicação de cursos e o número de alunos ingressantes no ensino superior. Os autores identificaram que a exclusiva presença de "elites culturais e sociais" entre os discentes brasileiros, realidade muito comum na historia da educação superior no país, tem se alterado revelando um quadro bem mais heterogênio quanto à origem social e cultural dos estudantes. Contudo, argumentam que para alcançar uma democratização de sucesso no ensino superior, faz-se necessário medidas institucionais e sociais de atenção a estes alunos de forma a tornar mais efetiva a democratização do ensino superior.

Nessa lógica, Costa e Ferreira (2017) problematizam se tais políticas contribuem de forma efetiva com a democratização do acesso e da permanência na educação superior brasileira. Ademais, alertam para a necessidade de criação de uma política alternativa ao Prouni, no sentido de não somente 
promover bolsas de acesso, mas assegurar e garantir o ingresso e a permanência de estudantes que advêm das camadas populares, com medidas contínuas e efetivas para manter os jovens de baixa renda nos cursos: auxílio alimentação, transporte e custeio de materiais. Além disso, que possam assegurar aos egressos oportunidades de ingresso no mercado de trabalho, com políticas que incentivem o primeiro emprego, por meio de interações entre universidades e o setor produtivo, alinhado com políticas públicas de compensação à concentração de renda, para o enfrentamento da pobreza e, sobretudo, para fortalecer a rede educacional e demais políticas públicas (Franco, 2008; Ghelere, 2014; Pereira et al. 2016).

Assim, para que haja de fato uma democratização para o ingresso e a conclusão do curso superior no país, é preciso uma base sólida de igualdade para todos, com o Estado brasileiro considerando a equidade como justiça essencial para o desenvolvimento de seus cidadãos. Corrobora-se, portanto, com a Teoria da Justiça de Rawls, a qual alega que a justiça das leis e as políticas econômicas e sociais devem se orientar para a ampliação das expectativas para os menos favorecidos, respeitando as condições da igualdade equitativa de oportunidades e mantendo as liberdades iguais para todos (Silva, 1998; Rawls, 1997), sob a perspectiva não apenas pela luta e garantia de direitos, mas pela emancipação humana.

Quanto ao Programa de Apoio a Planos de Reestruturação e Expansão das Universidades Federais (REUNI), este integra o Plano de Desenvolvimento da Educação (PDE) em reconhecimento do papel estratégico das universidades federais para o desenvolvimento econômico e social. Instituído pelo Decreto $n^{\circ}$ 6.096/ 2007, o REUNI teve seu início em 2008 e conclusão prevista para 2012 (Ministério da Educaçao, 2009). De acordo com Camilo (2014), os princípios e estratégias que orientaram esse programa estiveram presentes em alguma medida no contexto da reforma das universidades brasileiras pensada nos anos 1980. Porém, só foram implementadas, muito timidamente, ao longo dos Governos FHC (1995-2003), e com maior força nos Governos Lula (2003-2010) e no primeiro mandato do Governo Dilma (2010-2014). O principal objetivo do REUNI refere sobre a ampliação do acesso e permanência no ensino superior público, por meio de expansões físicas, acadêmicas e pedagógicas na rede federal, com: o aumento de vagas nos cursos de graduação; a ampliação de ofertas de cursos noturnos; assegurando a qualidade por meio de inovações acadêmicas; com a criação de novos campi; e a otimização do aproveitamento dos recursos humanos e infraestrutura das instituições federais de educação superior, com metas voltadas para a diminuição das desigualdades sociais no país (Ministério da Educação, 2009).

A adesão ao REUNI por parte da Instituição Federais de Ensino Superior (IFES) foi dividida em duas chamadas, em que das 54 universidades federais somente uma não aderiu: 42 IFES aderiram na primeira chamada e 11 na segunda chamada (Quadro 1).

Em 2008, logo no primeiro ano de execução do REUNI, o número de vagas em cursos presenciais de graduação teve um aumento de 14.826 novas vagas passando de 132.451 para um total de 147.277 vagas (Ministério da Educação, 2009). Houve um crescimento também no número de cursos de graduação presencial que passou de 2.326 para 2.552. Quanto a ampliação e readequação da infraestrutura física das universidades federais foram 327 o número total de obras realizadas. No que diz respeito à interiorização, foram criados 104 novos campi que, em conjunto com os 151 já existentes, representam a presença das universidades federais em 235 municípios brasileiros (Ministério da Educação, 2009).

O Relatório da Comissão, constituída pela Portaria n. ${ }^{0}$ 126/2012, para análise da expansão das universidades federais, confirma que o REUNI foi articulado como um importante processo no caminho do fortalecimento do principal objetivo de uma universidade, além de sua importância e sucesso de implantação. Traz como consideráveis resultados do programa o aumento das vagas, de matrículas e o aumento do número de campi, interiorizando a universidade pública no Brasil. No período de 2003 a 2010 foram criadas 14 universidades como parte do esforço empreendido pelo Governo Federal para a interiorização do ensino superior público, além da integração com os países da América do Sul e do Caribe e países lusófonos, em especial os africanos (Ministério da Educação, 2012). 
Quadro 1. Lista da Instituições Federais de Ensino Superior que adirarma ao REUNI

\begin{tabular}{|c|c|}
\hline & \\
\hline 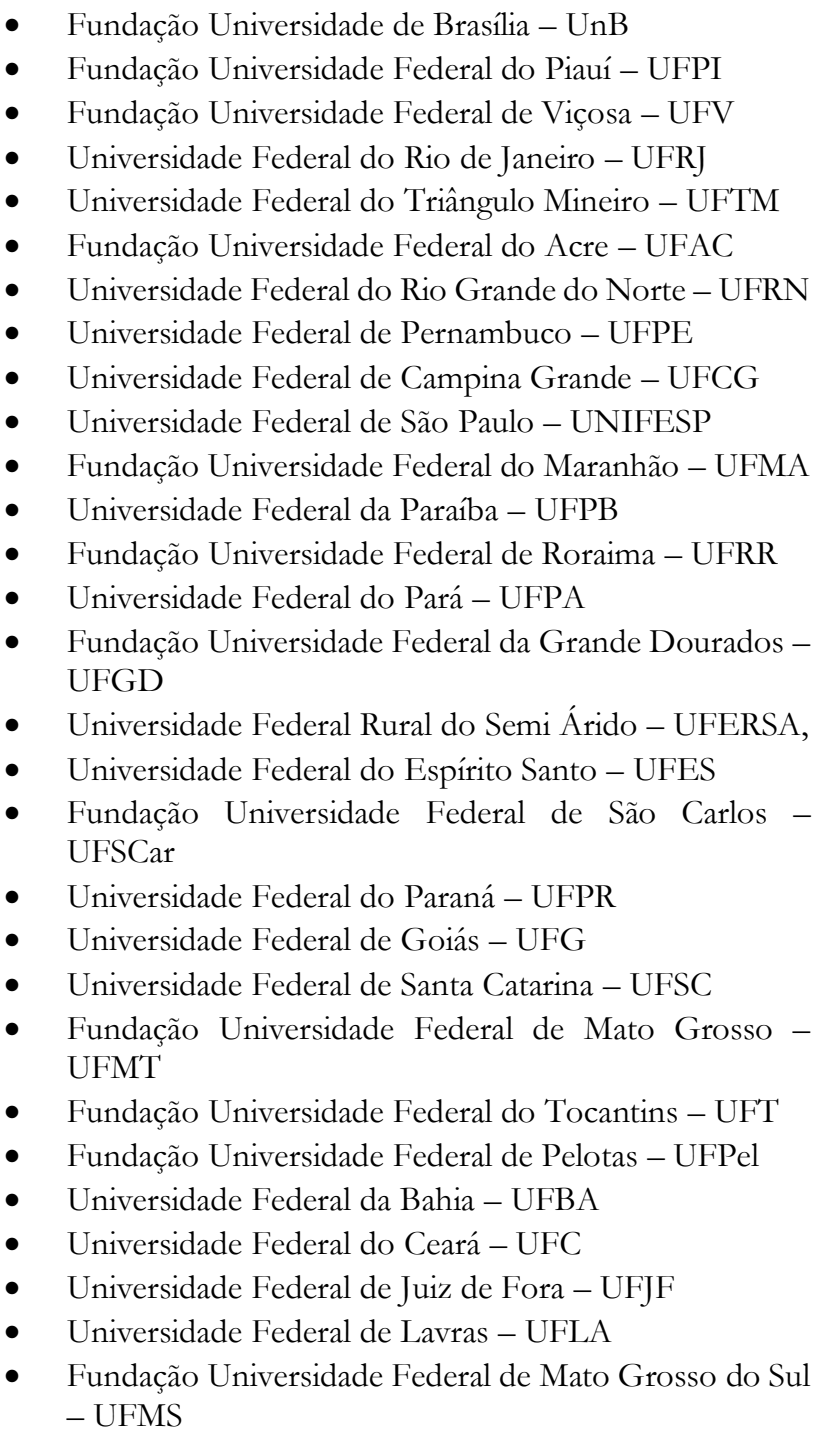 & 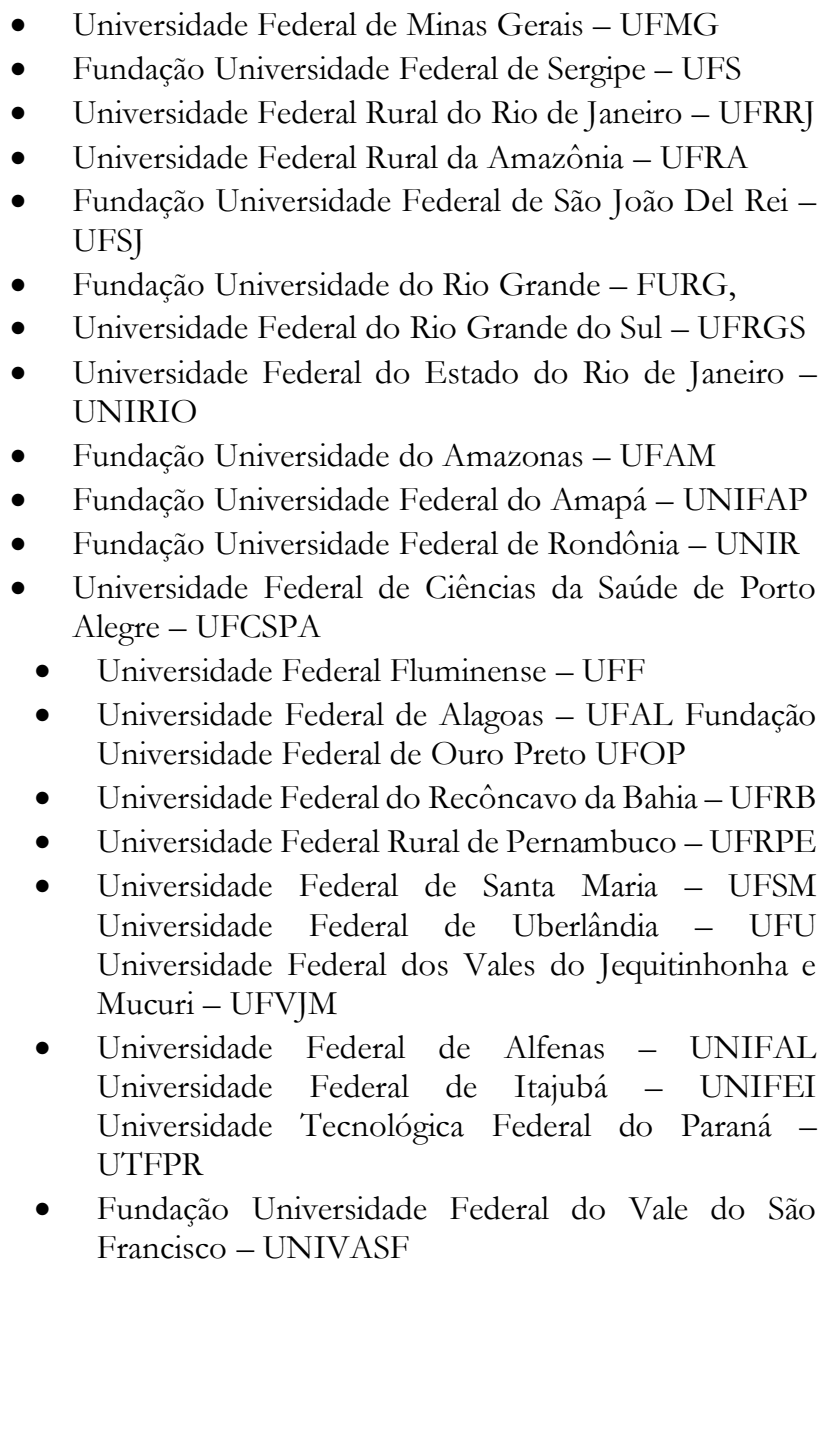 \\
\hline
\end{tabular}

Fonte: Ministério da Educação (MEC)

O referido relatório também ressalta que no período de implementação do REUNI houve um grande salto no número de docentes efetivos com a autorização de abertura de 21.786 novas vagas docentes, por meio de concurso público, e a consequente redução de $64 \%$ de docentes substitutos. Além do mais, o programa contribuiu para minimizar as desigualdades sociais entre os alunos garantindo condições de permanência e acesso acadêmico por meio do investimento do Programa Nacional de Assistência Estudantil (PNAES), que tem como objetivo promover a permanência de estudantes em situação de vulnerabilidade social nas universidades federais e viabilizar a igualdade de oportunidades entre todos os estudantes e contribuir para a melhoria do desempenho acadêmico. Demonstra que no período de expansão, para além das vagas públicas no ensino de graduação, houve um aumento significativo no número de bolsas de pós-graduação - demanda social - concedidas pela Capes, além da pópria expansão do setor no país (Ministério da Educação, 2012).

Contudo, Camilo (2014) aponta o processo de dificuldades para que a universidade pública federal se mantenha autônoma, quando afirma que "setores externos à instituição, principalmente os governos e o mercado econômico, em níveis local e global, têm cada vez mais poder na definição dos rumos da universidade" (p. 254). No caso do REUNI, a autora destaca os interesses econômicos que pautaram o programa, orientado pelos ditames do Banco Mundial, com quantidade insuficiente de vagas criadas para a realidade brasileira e verbas condicionadas ao cumprimento de metas. Além disso, a adesão 
"voluntária" ao programa foi conduzida a partir de dimensões previamente definidas pelo Governo, em contradição à autonomia das universidades.

Duquia e Borges (2016), em sua pesquisa com base no estudo de caso da Universidade Federal de Pelotas, abordaram o REUNI como uma espécie de contrato de gestão num processo de empresarização da referida instituição. Apontaram para a lógica neoliberal do Estado na forma de reestruturação do seu aparelho e instâncias de gestão, que, no caso da educação, mais precisamente o ensino superior, transformaram as universidades na condição de empresas ao implementarem relações de contrato e de cumprimento de metas. Tal lógica é inclusive retomada com mais força em tempos atuais, sob o Governo Jair Bolsonaro, por meio da proposta do Programa "Future-se/Fature-se", de forma avassaladora, ao interferir na gestão, na autonomia e na organização didático-científica, na pesquisa e na extensão da universidade brasileira, ao colocá-la sob a lógica das Organizações Sociais, tornando o seu patrimônio físico e intelectual sob a lógica do mercado.

Considerando, portanto, que o ensino superior brasileiro passou por significativas reformas e transformações ao longo tempo, focaremos na análise acerca do impacto das políticas educacionais dos Governos do Partido dos Trabalhadores (Prouni, Fies e Reuni) no perfil dos estudantes de graduação em Psicologia, considerando seu histórico elitista.

\section{MÉTODO}

Trata-se de um estudo documental, a partir de informações primárias retiradas dos microdados do Censo do Ensino Superior no Brasil e do Exame Nacional do Desempenho dos Estudantes (ENADE), divulgados em domínio público pelo Ministério da Educação (MEC). Os dados do ciclo do ENADE 2015 são somente de estudantes concludentes totalizando 549.488 estudantes de 26 cursos do ensino superior com grau acadêmico de bacharel e tecnológico. No curso de Psicologia foram avaliados 26.644 estudantes, sendo 4.550 de IES públicas e 22.094 em IES privadas. Para efeito desse estudo, selecionamos apenas os estudantes de Instituições de Ensino Superior (IES) privadas beneficiados ou não por políticas de acesso ao ensino superior e os de Instituições Federais de Ensino Superior (IFES) para compor a amostra final de 18.788 estudantes.

Para traçar o panorama dos cursos a análise foi baseada na descrição de frequências. A análise dos perfis dos estudantes foi realizada considerando sete grupos: "autofinanciados"; beneficiados pela política do "PROUNI integral", "PROUNI parcial", combinado "PROUNI parcial e FIES"; financiados pelo "FIES"; oriundos de Instituições Federais de Ensino Superior (IFES) que aderiram aos programas de expansão "REUNI" e aqueles oriundos de IFES que não aderiram aos mesmos programas, que denominamos "NÃO REUNI".

A partir da classificação dos estudantes, conforme a sua vinculação a uma instituição privada ou a uma IFES pertencentes ou não às políticas de acesso ao ensino superior, foi analisada a distribuição dos sujeitos nos sete grupos com base em um conjunto de treze variáveis, sendo elas: etnia (1); estado civil (2); renda familiar (3); situação financeira do candidato (4); situação de trabalho exceto estágio ou bolsa (5); escolarização do pai (6); escolarização da mãe (7); alguém da família concluiu o ensino superior (8); tipo de escola que cursou o ensino médio (9); modalidade de ensino médio que concluiu (10); porte do município (11); ingresso por meio de ação afirmativa ou inclusão social (12) e o tipo de bolsa acadêmica que recebe (13).

A análise foi realizada por meio do Software Statistical Package for the Social Sciences (SPSS) for Windows versão 21 , com base no teste qui-quadrado $(\chi 2)$ de independência e grau de significância 0,05 (p $<0,05)$, para verificar diferenças significativas ou não quanto as características investigadas entre os sete grupos e inferir associações entre as variáveis e os grupos. Vale ressaltar que neste estudo os sujeitos com respostas ausentes foram eliminados. A partir disso, tabelas de frequência foram construídas para facilitar a visualização da distribuição.

\section{RESULTADOS E DISCUSSÕES}

No geral, participaram do ENADE, no ciclo de 2015, na condição de concludentes do curso de Psicologia das universidades privadas e federais, o total de 18.788 estudantes. Desse total, 2.746 eram 
estudantes oriundos do setor das federais, cujos cursos aderiram ou não ao Programa REUNI (6,9\% e 7,8\%, respectivamente). Os demais, cerca de 16.042 estudantes eram do setor privado, sendo $9 \%$ de estudantes beneficiados com o PROUNI Integral, 2,9\% com o PROUNI Parcial, 3,1\% combinando PROUNI Parcial e FIES, 26,2\% com FIES e 44,2\% autofinanciados.

Comparando esses dados com aqueles apresentados pela pesquisa de Yamamoto, Seixas e Falcão (2011), observa-se os efeitos das políticas educacionais dos Governos do PT dinamizando o setor do ensino superior no país e, particularmente, nos cursos de graduação em Psicologia. Nestes, tivemos um maior percentual de crescimento de estudantes no setor público, que saltou de 10,1\% em 2006 para $14,6 \%$ em 2015, enquanto no setor privado foi de $83,5 \%$ para $85,38 \%$, no mesmo período. Além disso, contribuiu para diminuir o histórico desequilíbrio regional quanto a oferta de vagas no sistema, fazendo cair a concentração de estudantes nas regiões Sudeste (57,0\% em 2006 para 43,3\% em 2015) e Sul (19,1\% para $18,3 \%$ ), enquanto no Nordeste elevou de $12,5 \%$ para $24,2 \%$.

Sobre o perfil da amostra dos concludentes dos cursos de Psicologia que participaram do ciclo do ENADE em 2015, observa-se que foi composta, em sua maioria, por mulheres $(82,9 \%)$, com idade entre 20 e 26 anos (56,3\%), solteiras (72,6\%), declaradamente brancas (61,3\%), com renda familiar variando de zero até 4,5 salários mínimos (56\%). Ademais, referiram que os gastos com os estudos foram financiados por programas governamentais $(9,1 \%)$ ou pela família/outras pessoas $(41,6 \%)$; que não possuíam emprego (54,7\%); que cursaram todo o ensino médio em escola pública $(55,2 \%)$; que estavam vinculados a cursos de Psicologia que funcionavam em municípios de grande porte $(53,7 \%)$; que não ingressaram por meio de políticas de ação afirmativa ou inclusão social (83\%); e que não receberam qualquer tipo de bolsa acadêmica $(79,1 \%)$.

Quanto as treze variáveis analisadas, no que tange a Etnia, percebeu-se, a partir da Tabela 1, que os cursos de Psicologia ainda refletem um maior contingente de estudantes brancos.

Tabela 1. Etnia dos estudantes do curso de Psicologia beneficiados ou não pelas Políticas de acesso ao Ensino Superior das Universidades Privadas e Públicas.

\begin{tabular}{|c|c|c|c|c|c|c|c|c|c|c|c|c|c|c|}
\hline \multicolumn{15}{|c|}{ ETNIA } \\
\hline & \multicolumn{2}{|c|}{ AUTOFINANCIADOS } & \multicolumn{2}{|c|}{$\begin{array}{c}\text { PROUNI } \\
\text { INTEGRAL }\end{array}$} & \multicolumn{2}{|c|}{$\begin{array}{l}\text { PROUNI } \\
\text { PARCIAL }\end{array}$} & \multicolumn{2}{|c|}{ FIES } & \multicolumn{2}{|c|}{$\begin{array}{c}\text { PROUNI } \\
\text { PARCIAL } \\
\text { E FIES }\end{array}$} & \multicolumn{2}{|c|}{ REUNI } & \multicolumn{2}{|c|}{ NÃO REUNI } \\
\hline & $\mathbf{N}$ & $\%$ & $\mathbf{N}$ & $\%$ & $\mathbf{N}$ & $\%$ & $\mathbf{N}$ & $\%$ & $\mathbf{N}$ & $\%$ & $\mathbf{N}$ & $\%$ & $\mathbf{N}$ & $\%$ \\
\hline Branco & 5.754 & 30,6 & 843 & 4,5 & 284 & 1,5 & 2.786 & 14,8 & 297 & 1,6 & 686 & 3,7 & 871 & 4,6 \\
\hline Negro & 424 & 2,6 & 229 & 1,2 & 61 & 0,3 & 387 & 2,1 & 74 & 0,4 & 126 & 0,7 & 134 & 0,7 \\
\hline Pardo/Mulato & 1939 & 10,3 & 602 & 3,2 & 188 & 1,0 & 1635 & 8,7 & 199 & 1,1 & 448 & 2,4 & 429 & 2,3 \\
\hline $\begin{array}{c}\text { Amarelo } \\
\text { (de origem oriental) } \\
\end{array}$ & 136 & 0,7 & 11 & 0,1 & 6 & 0 & 75 & 0,4 & 7 & 0 & 16 & 0,1 & 16 & 0,1 \\
\hline $\begin{array}{l}\text { Indígena (ou de } \\
\text { origem indígena) }\end{array}$ & 55 & 0,3 & 9 & 0 & 3 & 0 & 35 & 0,2 & 3 & 0 & $11^{\mathrm{a}}$ & 0,1 & 9 & 0 \\
\hline TOTAL & 8.308 & 44,2 & 1.694 & 9,0 & 542 & 2,9 & 4.918 & 26,2 & 580 & 3,1 & 1.287 & 6,9 & 1.459 & 7,8 \\
\hline \multicolumn{15}{|c|}{$\chi^{2} 547,195$} \\
\hline \multicolumn{15}{|c|}{ Sig. 0,001* } \\
\hline
\end{tabular}

${ }^{*} p<0,05$, demonstrando significância.

Apesar deste ser um perfil que se mantém, se compararmos os dados do ENADE de 2015 com aqueles analisados por Yamamoto, Seixas e Falcão (2011) referentes ao ciclo de 2006, ressalta-se que houve uma sensível diminuição entre o percentual de estudantes que se declararam brancos (73,2\% para $61,3 \%$ ) e um aumento entre pardos/mulatos (19,3\% para $29 \%$ ) e negros (4,3\% para $8 \%)$. No estudo de Ristoff (2013), acerca da análise do perfil socioeconômico dos respondentes do questionário ENADE com base em dois ciclos, a autora verificou que houve uma redução do número de brancos nos campi universitários brasileiros, de $70 \%$ para $65 \%$, atribuindo a adoção de políticas como o PROUNI, o FIES e o REUNI como os principais vetores dessa mudança.

$\mathrm{Na}$ aplicação do teste qui-quadrado nesta variável, observou-se que a contagem real superou a contagem esperada, indicando relação entre a alternativa e a composição do grupo. Se considerarmos os sete grupos investigados, observamos uma maior incidência de estudantes pardos (16,4\%) e negros (4,7\%) beneficiados por políticas educacionais. A política que mais se destaca neste caso é o PROUNI nas suas modalidades Integral, Parcial e Combinado ao FIES, sendo respectivamente as modalidades de 
bolsa que têm maior impacto na entrada de pessoas negras nos cursos de Psicologia. Com relação a população indígena é o REUNI que tem maior impacto na entrada dessas pessoas nas universidades para cursar Psicologia, ainda que com percentuais extremamente baixos.

Quanto ao estado civil, como pode ser acompanhado pela Tabela 2, o maior percentual é de estudantes solteiros $(72,5 \%)$, seguido de estudantes casados $(20,3 \%)$.

Tabela 2. Estado civil dos estudantes do curso de Psicologia beneficiados ou não pelas Políticas de acesso ao Ensino Superior das Universidades Privadas e Públicas.

\begin{tabular}{|c|c|c|c|c|c|c|c|c|c|c|c|c|c|c|}
\hline \multicolumn{15}{|c|}{ ESTADO CIVIL } \\
\hline & \multicolumn{2}{|c|}{ AUTOFINANCIADOS } & \multicolumn{2}{|c|}{$\begin{array}{c}\text { PROUNI } \\
\text { INTEGRAL }\end{array}$} & \multicolumn{2}{|c|}{$\begin{array}{l}\text { PROUNI } \\
\text { PARCIAL }\end{array}$} & \multicolumn{2}{|c|}{ FIES } & \multicolumn{2}{|c|}{$\begin{array}{c}\text { PROUNI } \\
\text { PARCIAL } \\
\text { E FIES }\end{array}$} & \multicolumn{2}{|c|}{ REUNI } & \multicolumn{2}{|c|}{ NÃO REUNI } \\
\hline & $\mathbf{N}$ & $\%$ & $\mathbf{N}$ & $\%$ & $\mathbf{N}$ & $\%$ & $\mathbf{N}$ & $\%$ & $\mathbf{N}$ & $\%$ & $\mathbf{N}$ & $\%$ & $\mathbf{N}$ & $\%$ \\
\hline Solteiro & 5.702 & 30,3 & 1.285 & 6,8 & 427 & 2,3 & 3.396 & 18,1 & 403 & 2,1 & 1.107 & 5,9 & 1320 & 7,0 \\
\hline Casado & 2.004 & 10,7 & 280 & 1,5 & 88 & 0,5 & 1.074 & 5,7 & 133 & 0,7 & 130 & 0,7 & 94 & 0,5 \\
\hline $\begin{array}{l}\text { Separado/ } \\
\text { Divorciado }\end{array}$ & 349 & 1,9 & 55 & 0,3 & 10 & 0,1 & 247 & 1,3 & 21 & 0,1 & 11 & 0,1 & 12 & 0,1 \\
\hline Viúvo & 42 & 0,2 & 8 & 0 & 1 & 0 & 11 & 0,1 & 0 & 0 & 2 & 0 & 1 & 0 \\
\hline Outro & 211 & 1,1 & 66 & 0,4 & 16 & 0,1 & 190 & 1,0 & 23 & 0,1 & 37 & 0,2 & 32 & 0,2 \\
\hline TOTAL & 8.308 & 44,2 & 1.694 & 9,0 & 542 & 2,9 & 4.918 & 26,2 & 580 & 3,1 & 1.287 & 6,9 & 1.459 & 7,8 \\
\hline \multicolumn{15}{|c|}{$\chi^{2} 554,363$} \\
\hline \multicolumn{15}{|c|}{ Sig. 0,001* } \\
\hline
\end{tabular}

${ }^{*} p<0,05$, demonstrando significância.

Face às políticas, é visto que os casados, ainda que em menor percentual, estão em maior número nos grupos referentes ao PROUNI Integral e FIES. De acordo com a contagem esperada, identificou-se que os estudantes casados, separados e viúvos são atraídos por Políticas de Financiamento Estudantil (FIES) e PROUNI Parcial combinado ao FIES. O destaque com relação aos estudantes que não são solteiros corresponde a expectativa de que estes estudantes já possuam alguma renda, o que pode justificar tanto o fato deles se concentrarem no grupo de instituições privadas sem uso de bolsa ou financiamento, quanto de preencherem os requisitos para poder autofinanciarem o curso.

Tabela 3. Renda familiar dos estudantes do curso de Psicologia beneficiados ou não pelas Políticas de acesso ao Ensino Superior das Universidades Privadas e Públicas.

\begin{tabular}{|c|c|c|c|c|c|c|c|c|c|c|c|c|c|c|}
\hline \multicolumn{15}{|c|}{ RENDA FAMILIAR } \\
\hline & \multicolumn{2}{|c|}{ AUTOFINANCIADOS } & \multicolumn{2}{|c|}{$\begin{array}{c}\text { PROUNI } \\
\text { INTEGRAL }\end{array}$} & \multicolumn{2}{|c|}{$\begin{array}{l}\text { PROUNI } \\
\text { PARCIAL }\end{array}$} & \multicolumn{2}{|c|}{ FIES } & \multicolumn{2}{|c|}{$\begin{array}{c}\text { PROUNI } \\
\text { PARCIAL } \\
\text { E FIES }\end{array}$} & \multicolumn{2}{|c|}{ REUNI } & \multicolumn{2}{|c|}{$\begin{array}{c}\text { NÃO } \\
\text { REUNI }\end{array}$} \\
\hline & $\mathbf{N}$ & $\%$ & $\mathbf{N}$ & $\%$ & $\mathbf{N}$ & $\%$ & $\mathbf{N}$ & $\%$ & $\mathbf{N}$ & $\%$ & $\mathbf{N}$ & $\%$ & $\mathbf{N}$ & $\%$ \\
\hline Até $1,5 \mathrm{SM}$ & 427 & 2,3 & 375 & 2,0 & 66 & 0,4 & 834 & 4,4 & 114 & 0,6 & $170^{\mathrm{a}}$ & 0,9 & 142 & 0,8 \\
\hline De 1,5 a 3 SM & 1247 & 6,6 & 750 & 4,0 & 203 & 1,1 & 1.668 & 8,9 & 225 & 1,2 & 289 & 1,5 & 266 & 1,4 \\
\hline De 3 a 4,5 SM & 1437 & 7,6 & 388 & 2,1 & 146 & 0,8 & 1.164 & 6,2 & 138 & 0,7 & 241 & 1,3 & 228 & 1,2 \\
\hline De 4,5 a 6 SM & 1.269 & 6,8 & 122 & 0,6 & 71 & 0,4 & 605 & 3,2 & 65 & 0,3 & 178 & 0,9 & 194 & 1,0 \\
\hline De 10 a 30 SM & 1.673 & 8,9 & 2 & 0,0 & 4 & 0,0 & 149 & 0,8 & 2 & 0,0 & 163 & 0,9 & 249 & 1,3 \\
\hline Acima de $30 \mathrm{SM}$ & 389 & 2,1 & 0 & 0,0 & 0 & 0,0 & 6 & 0,0 & 0 & 0,0 & 23 & 0,1 & 60 & 0,3 \\
\hline TOTAL & 8.308 & 44,2 & 1.694 & 9,0 & 542 & 2,9 & 4.918 & 26,2 & 580 & 3,1 & 1.287 & 6,9 & 1.459 & 7,8 \\
\hline \multicolumn{15}{|c|}{$\chi^{2} 3743,171$} \\
\hline \multicolumn{15}{|c|}{ Sig. 0,001* } \\
\hline
\end{tabular}

\section{${ }^{*} p<0,05$, demonstrando significância.}

Em relação à renda familiar, de acordo com a Tabela 3, 56\% dos estudantes indicaram possuir renda abaixo de quatro e meio salários mínimos, sendo que os alunos de IES privadas beneficiados pelas Políticas de acesso como o PROUNI e FIES têm um índice de renda ainda menor, variando entre 1,5 a 3 salários, quando comparados aos outros grupos de estudantes analisados nessa pesquisa. Considerando a diferença entre a contagem real e a contagem esperada, é o PROUNI Integral o que mais aumenta a probabilidade de estudantes com renda de zero a 3 salários de cursarem Psicologia, ao passo que o REUNI agrega estudantes com condições econômicas mais favoráveis.

No tocante à situação financeira do próprio estudante, percebemos uma maior parcela $(50,7 \%)$ sem renda e que não trabalha $(54,7 \%)$, tendo seus gastos financiados por programas governamentais, pela família ou por outras pessoas, sendo que estes estão mais concentrados nas Instituições Federais de Ensino Superior (IFES). Por outro lado, são os alunos de instituições privadas, 
beneficiados ou não por políticas de acesso, que tendem a trabalhar e possuir maior carga horária de trabalho.

Quanto ao nível de escolaridade dos progenitores, como observado na tabela 4, o destaque é para aqueles com pai $(75,9 \%)$ e mãe $(70,9 \%)$ com baixa escolaridade, variando entre não possuir escolaridade e ensino médio.

Tabela 4. Escolaridade dos pais dos estudantes do curso de Psicologia beneficiados ou não pelas Políticas de acesso ao Ensino Superior das Universidades Privadas e Públicas

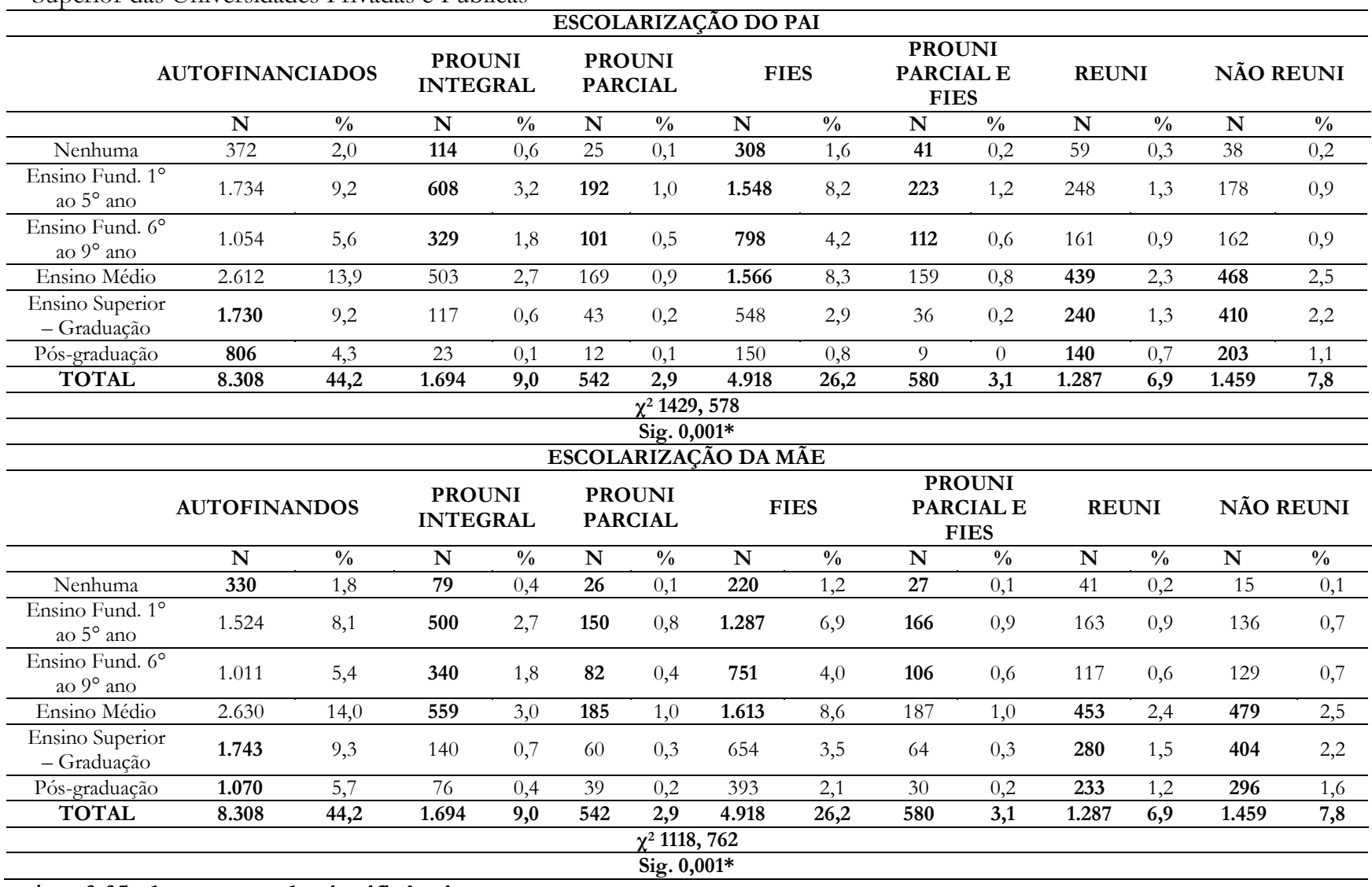

${ }^{*} p<0,05$, demonstrando significância.

Os alunos de IES privadas beneficiados com PROUNI e FIES são aqueles que mais possuem pais com menor escolarização, tanto em termos de tendência, conforme indica a contagem esperada do teste qui-quadradro, quanto em termos percentuais: $35,9 \%$ e 33,5\%, referente a pais e mães, respetivamente. Além disso, é observado que as mães possuem maior escolaridade que os pais. Avalia-se ainda, de forma mais específica, que o PROUNI (integral e parcial) como o principal vetor de acesso de estudantes, com progenitores com baixo nível escolar, para cursarem Psicologia. Ainda sobre o nível escolar dos familiares, a maioria dos estudantes de Psicologia do Brasil $(73,1 \%)$ tem alguém na família com ensino superior concluso.

Quanto ao resultado da análise do qui-quadrado dos alunos beneficiados pelo PROUNI e FIES comparado aos alunos de IFES e alunos de IES privadas não beneficiados por políticas, observase que os primeiros têm maiores possibilidades de familiares não terem cursado o ensino superior. Em percentuais, o PROUNI Integral é o principal responsável por possibilitar o acesso de pessoas ao curso de Psicologia que não têm nenhum ente familiar com ensino superior concluído, indicando que por meio deste programa o estudante tem a possibilidade de ser o primeiro no seio familiar a ter um diploma de curso superior.

Nesse sentido, Felicetti e Cabrera (2017) apontam o PROUNI como fator que colaborou para o acesso de um novo perfil de estudantes não somente nas universidades, mas nos núcleos familiares, nas comunidades e em um contexto social maior. Ser o primeiro da família a se graduar proporciona uma mudança de perspectivas e posturas no seio familiar ao passo que possibilita a construção de um capital 
cultural podendo estimular outros familiares a ingressaram no ensino superior, ou a voltarem para os estudos, refletindo assim nas gerações futuras (Felicetti \& Cabrera, 2017; Felicetti et al., 2014).

No que se refere ao tipo de escola em que cursou o ensino médio, conforme a Tabela 5 , a maioria dos estudantes brasileiros de Psicologia estudou todo o ensino médio em escola pública (55,2\%), sendo que mais da metade deles foram, concomitantemente, beneficiados com o PROUNI e FIES.

Tabela 5. Tipo de escola em que os estudantes do curso de Psicologia beneficiados ou não pelas Políticas de acesso ao Ensino Superior das Universidades Privadas e Públicas cursaram o Ensino Médio.

\begin{tabular}{|c|c|c|c|c|c|c|c|c|c|c|c|c|c|c|}
\hline \multicolumn{15}{|c|}{ TIPO DE ESCOLA QUE CURSOU O ENSINO MÉDIO } \\
\hline \multicolumn{3}{|c|}{ AUTOFINANCIADOS } & \multicolumn{2}{|c|}{$\begin{array}{c}\text { PROUNI } \\
\text { INTEGRAL }\end{array}$} & \multicolumn{2}{|c|}{$\begin{array}{l}\text { PROUNI } \\
\text { PARCIAL }\end{array}$} & \multicolumn{2}{|c|}{ FIES } & \multicolumn{2}{|c|}{$\begin{array}{c}\text { PROUNI } \\
\text { PARCIAL } \\
\text { E FIES }\end{array}$} & \multicolumn{2}{|c|}{ REUNI } & \multicolumn{2}{|c|}{$\begin{array}{c}\text { NÃO } \\
\text { REUNI }\end{array}$} \\
\hline & $\mathbf{N}$ & $\%$ & $\mathbf{N}$ & $\%$ & $\mathbf{N}$ & $\%$ & $\mathbf{N}$ & $\%$ & $\mathbf{N}$ & $\%$ & $\mathbf{N}$ & $\%$ & $\mathbf{N}$ & $\%$ \\
\hline $\begin{array}{c}\text { Toda em escola } \\
\text { pública }\end{array}$ & $\begin{array}{c}3.44 \\
3\end{array}$ & 18,3 & 1.556 & 8,3 & 498 & 2,7 & 3.251 & 17,3 & 521 & 2,8 & 536 & 2,9 & 552 & 2,9 \\
\hline $\begin{array}{c}\text { Todo em escola } \\
\text { privada ou } \\
\text { particular }\end{array}$ & 3.717 & 19,8 & 75 & 0,4 & 14 & 0,1 & 1087 & 5,8 & 27 & 0,1 & 631 & 3,4 & 811 & 4,3 \\
\hline Todo no exterior & 14 & 0,1 & 0 & 0,0 & 0 & 0,0 & 2 & 0,0 & 0 & 0,0 & 2 & 0,0 & 0 & 0,0 \\
\hline $\begin{array}{l}\text { A maior parte em } \\
\text { escola pública }\end{array}$ & 547 & 2,9 & 39 & 0,2 & 23 & 0,1 & 350 & 1,9 & 16 & 0,1 & 42 & 0,2 & 42 & 0,2 \\
\hline $\begin{array}{c}\text { A maior parte em } \\
\text { escola privada ou } \\
\text { particular }\end{array}$ & 538 & 2,9 & 24 & 0,1 & 7 & 0,0 & 223 & 1,2 & 16 & 0,1 & 74 & 0,4 & 46 & 0,2 \\
\hline $\begin{array}{c}\text { Parte no Brasil, } \\
\text { parte no exterior }\end{array}$ & 49 & 0,3 & 0 & 0,0 & 0 & 0,0 & 5 & 0,0 & 0 & 0,0 & 2 & 0,0 & 8 & 0,0 \\
\hline TOTAL & $\begin{array}{c}8.30 \\
8\end{array}$ & 44,2 & 1.694 & 9,0 & 542 & 2,9 & 4.918 & 26,2 & 580 & 3,1 & 1.287 & 6,9 & 1.459 & 7,8 \\
\hline \multicolumn{15}{|c|}{$\chi^{2} 2974,154$} \\
\hline \multicolumn{15}{|c|}{ Sig. 0,001* } \\
\hline
\end{tabular}

$* \overline{p<0,05, \text { demonstrando significância. }}$

Em termos percentuais, sugere-se que o principal responsável por ampliar o acesso dos alunos oriundos de escolas públicas de cursar Psicologia é o PROUNI, nas modalidades de oferta de bolsas integrais e parciais. Além disso, apuramos que a maioria concluiu o ensino médio na modalidade tradicional (83,5\%). Entretanto, a contagem esperada do teste qui-quadrado demonstrou que os grupos formados a partir dos programas REUNI, PROUNI (Integral, Parcial apenas e Parcial combinado ao FIES) e FIES têm maiores probabilidades de serem compostos por estudantes concluintes de modalidades de ensino médio profissionalizante técnico, profissionalizante magistério, EJA ou supletivo e outro. O PROUNI com oferta de bolsas integrais é o principal responsável por alcançar os alunos que vêm de ensino médio técnico profissionalizante, magistério e outro. Quanto àqueles que concluíram o ensino médio pela modalidade EJA ou supletivo, o FIES foi o principal responsável por estarem no ensino superior.

Consoante a Tabela 6, a maioria dos estudantes de Psicologia (53,6\%) de Instituições de Ensino Superior (IES) públicas e privadas no Brasil estão concentrados em munícipios de grande porte.

Tabela 6. Porte do município em que os estudantes do curso de Psicologia beneficiados ou não pelas Políticas de acesso ao Ensino Superior das Universidades Privadas e Públicas.

\begin{tabular}{|c|c|c|c|c|c|c|c|c|c|c|c|c|c|c|}
\hline \multicolumn{15}{|c|}{ PORTE DO MUNICÍPIO } \\
\hline & \multicolumn{2}{|c|}{ AUTOFINANCIADOS } & \multicolumn{2}{|c|}{$\begin{array}{c}\text { PROUNI } \\
\text { INTEGRAL }\end{array}$} & \multicolumn{2}{|c|}{$\begin{array}{l}\text { PROUNI } \\
\text { PARCIAL }\end{array}$} & \multicolumn{2}{|c|}{ FIES } & \multicolumn{2}{|c|}{$\begin{array}{c}\text { PROUNI } \\
\text { PARCIAL } \\
\text { E FIES }\end{array}$} & \multicolumn{2}{|c|}{ REUNI } & \multicolumn{2}{|c|}{$\begin{array}{c}\text { NÃO } \\
\text { REUNI }\end{array}$} \\
\hline & $\mathbf{N}$ & $\%$ & $\mathbf{N}$ & $\%$ & $\mathbf{N}$ & $\%$ & $\mathbf{N}$ & $\%$ & $\mathbf{N}$ & $\%$ & $\mathbf{N}$ & $\%$ & $\mathbf{N}$ & $\%$ \\
\hline Pequeno Porte & 159 & 0,8 & 69 & 0,4 & 17 & 0,1 & 187 & 1,0 & 18 & 0,1 & 68 & 0,4 & 16 & 0,1 \\
\hline $\begin{array}{l}\text { Médio Pequeno } \\
\text { Porte }\end{array}$ & 520 & 2,8 & 158 & 0,8 & 33 & 0,2 & 485 & 2,6 & 39 & 0,2 & 254 & 1,4 & 20 & 0,1 \\
\hline Médio Porte & 1.699 & 9 & 380 & 2,0 & 133 & 0,7 & 1.300 & 6,9 & 129 & 0,7 & 349 & 1,9 & 161 & 0,9 \\
\hline Médio Grande Porte & 1.134 & 6 & 233 & 1,2 & 61 & 0,3 & 665 & 3,5 & 74 & 0,4 & 219 & 1,2 & 124 & 0,7 \\
\hline Grande Porte & 4.796 & 25,5 & 854 & 4,5 & 298 & 1,6 & 2.281 & 12,1 & 320 & 1,7 & 347 & 2,1 & 1.138 & 6,1 \\
\hline TOTAL & 8.308 & 44,2 & 1.694 & 9,0 & 542 & 2,9 & 4.918 & 26,2 & 580 & 3,1 & 1.287 & 6,9 & 1.459 & 7,8 \\
\hline \multicolumn{15}{|c|}{$\chi^{2} 1007,836$} \\
\hline \multicolumn{15}{|c|}{ Sig. 0,001* } \\
\hline
\end{tabular}

$*$ p<0,05, demonstrando significância. 
Percebe-se ainda que as chances de pessoas cursarem Psicologia oriundas de municípios de pequeno, pequeno médio, médio e médio grande, ampliaram-se a partir dos programas REUNI, PROUNI Integral e FIES. Nas universidades públicas foi o REUNI, pela própria natureza do programa, que mais contribuiu para o ingresso de alunos oriundos de localidades de menor porte populacional e do interior nos cursos de Psicologia. Já nas IES privadas foi o FIES, com exceção dos estudantes de município de pequeno porte, cujo destaque foi o PROUNI Integral.

Tabela 7. Ingresso dos estudantes do curso de Psicologia beneficiados ou não pelas Políticas de acesso ao Ensino Superior das Universidades Privadas e Públicas por meio de políticas de ação afirmativa ou inclusão social.

\begin{tabular}{|c|c|c|c|c|c|c|c|c|c|c|c|c|c|c|}
\hline \multicolumn{15}{|c|}{ INGRESSO POR MEIO DE POLÍTICAS DE AÇÃO AFIRMATIVA OU INCLUSÃO SOCIAL } \\
\hline & \multicolumn{2}{|c|}{ AUTOFINANCIADOS } & \multicolumn{2}{|c|}{$\begin{array}{c}\text { PROUNI } \\
\text { INTEGRAL }\end{array}$} & \multicolumn{2}{|c|}{$\begin{array}{l}\text { PROUNI } \\
\text { PARCIAL }\end{array}$} & \multicolumn{2}{|c|}{ FIES } & \multicolumn{2}{|c|}{$\begin{array}{l}\text { PROUNI } \\
\text { PARCIAL E } \\
\text { FIES }\end{array}$} & \multicolumn{2}{|c|}{ REUNI } & \multicolumn{2}{|c|}{$\begin{array}{c}\text { NÃO } \\
\text { REUNI }\end{array}$} \\
\hline & $\mathbf{N}$ & $\%$ & $\mathbf{N}$ & $\%$ & $\mathbf{N}$ & $\%$ & $\mathbf{N}$ & $\%$ & $\mathbf{N}$ & $\%$ & $\mathbf{N}$ & $\%$ & $\mathbf{N}$ & $\%$ \\
\hline Não & 8.062 & 42,9 & 452 & 2,4 & 264 & 1,4 & 4.399 & 23,4 & 313 & 1,7 & 1.023 & 5,4 & 1.092 & 5,8 \\
\hline $\begin{array}{l}\text { Sim por critério } \\
\text { étnico racial }\end{array}$ & 13 & 0,1 & 78 & 0,4 & 14 & 0,1 & 9 & 0,0 & 16 & 0,1 & 37 & 0,2 & 56 & 0,3 \\
\hline $\begin{array}{c}\text { Sim por critério de } \\
\text { renda }\end{array}$ & 58 & 0,3 & 268 & 1,4 & 63 & 0,3 & 229 & 1,2 & 44 & 0,2 & 8 & 0,0 & 19 & 0,1 \\
\hline $\begin{array}{c}\text { Sim por ter } \\
\text { estudado em escola } \\
\text { pública ou } \\
\text { particular com } \\
\text { bolsa de estudos } \\
\end{array}$ & 21 & 0,1 & 349 & 1,9 & 103 & 0,5 & 118 & 0,6 & 112 & 0,6 & 177 & 0,9 & 212 & 1,1 \\
\hline $\begin{array}{l}\text { Sim por sistema } \\
\text { que combina dois } \\
\text { ou mais critérios } \\
\text { anteriores }\end{array}$ & 14 & 0,1 & 514 & 2,7 & 82 & 0,4 & 47 & 0,3 & 82 & 0,4 & 31 & 0,2 & 72 & 0,4 \\
\hline $\begin{array}{l}\text { Sim por sistemas } \\
\text { diferentes dos } \\
\text { anteriores }\end{array}$ & 140 & 0,7 & 33 & 0,2 & 16 & 0,1 & 116 & 0,6 & 13 & 0,1 & 11 & 0,1 & 8 & 0,0 \\
\hline TOTAL & 8.308 & 44,2 & 1.694 & 9,0 & 542 & 2,9 & 4.918 & 26,2 & 580 & 3,1 & 1.287 & 6,9 & 1.459 & 7,8 \\
\hline \multirow{2}{*}{\multicolumn{15}{|c|}{$\chi^{2} 7672,209$}} \\
\hline & & & & & & & & & & & & & & \\
\hline
\end{tabular}

\section{$* p<0,05$, demonstrando significância.}

Por outro lado, segundo a Tabela 7, 83\% dos estudantes de Psicologia não ingressaram por meio de políticas de ação afirmativa ou inclusão social. No entanto, nota-se que os estudantes de instituições privadas beneficiados pelo PROUNI, na modalidade de ofertas de bolsas integrais, ingressam por critérios étnicos raciais e de renda, ou pelo critério de ter estudado em escola pública ou privada com bolsas de estudo, ou ainda por combinar dois ou mais critérios anteriores. Tais aspectos revelam o programa como o principal vetor de acesso de estudantes afetados por condições socioeconômicas desiguais.

Podemos acompanhar pela Tabela 8 que a maioria dos discentes de Psicologia não recebe qualquer tipo de bolsa acadêmica (79,1\%). Entretanto, os alunos de Instituições Federais de Ensino Superior (IFES) tendem a receber mais bolsas acadêmicas que os outros.

Tabela 8. Tipo de bolsa acadêmica que os estudantes do curso de Psicologia beneficiados ou não pelas Políticas de acesso ao Ensino Superior das Universidades Privadas e Públicas recebe.

\begin{tabular}{|c|c|c|c|c|c|c|c|c|c|c|c|c|c|c|}
\hline \multicolumn{15}{|c|}{ TIPO DE BOLSA ACADÊMICA QUE RECEBE } \\
\hline & \multicolumn{2}{|c|}{ AUTOFINANCIADOS } & \multicolumn{2}{|c|}{$\begin{array}{c}\text { PROUNI } \\
\text { INTEGRAL }\end{array}$} & \multicolumn{2}{|c|}{$\begin{array}{l}\text { PROUNI } \\
\text { PARCIAL }\end{array}$} & \multicolumn{2}{|c|}{ FIES } & \multicolumn{2}{|c|}{$\begin{array}{c}\text { PROUNI } \\
\text { PARCIAL E } \\
\text { FIES }\end{array}$} & \multicolumn{2}{|c|}{ REUNI } & \multicolumn{2}{|c|}{$\begin{array}{c}\text { NÃO } \\
\text { REUNI }\end{array}$} \\
\hline & $\mathbf{N}$ & $\%$ & $\mathbf{N}$ & $\%$ & $\mathbf{N}$ & $\%$ & $\mathbf{N}$ & $\%$ & $\mathbf{N}$ & $\%$ & $\mathbf{N}$ & $\%$ & $\mathbf{N}$ & $\%$ \\
\hline Nenhuma & 7.279 & 38,7 & 1365 & 7,3 & 486 & 2,6 & 4258 & 22,7 & 504 & 2,7 & 464 & 2,5 & 481 & 2,6 \\
\hline $\begin{array}{c}\text { Bolsa de Iniciação } \\
\text { Científica }\end{array}$ & 387 & 2,1 & 137 & 0,7 & 22 & 0,1 & 156 & 0,8 & 22 & 0,1 & 285 & 1,5 & 385 & 2,0 \\
\hline Bolsa de Extensão & 116 & 0,6 & 49 & 0,3 & 11 & 0,1 & 81 & 0,4 & 18 & 0,1 & 200 & 1,1 & 314 & 1,7 \\
\hline $\begin{array}{c}\text { Bolsa de Monitoria ou } \\
\text { Tutoria }\end{array}$ & 201 & 1,1 & 57 & 0,3 & 10 & 0,1 & 113 & 0,6 & 13 & 0,1 & 115 & 0,6 & 117 & 0,6 \\
\hline Bolsa Pet & 53 & 0,3 & 22 & 0,1 & 0 & 0,0 & 26 & 0,1 & 2 & 0,0 & 134 & 0,7 & 84 & 0,4 \\
\hline Outro Tipo de Bolsa & 272 & 1,4 & 64 & 0,3 & 13 & 0,1 & 284 & 1,5 & 21 & 0,1 & 89 & 0,5 & 78 & 0,7 \\
\hline TOTAL & 8.308 & 44,2 & 1.694 & 9,0 & 542 & 2,9 & 4.918 & 26,2 & 580 & 3,1 & 1.287 & 6,9 & 1.459 & 7,8 \\
\hline \multicolumn{15}{|c|}{$\chi^{2} 4967,535$} \\
\hline \multicolumn{15}{|c|}{ Sig. 0,001* } \\
\hline
\end{tabular}


Nesta lógica, é o programa REUNI o responsável por agregar maior número de estudantes que aderem a bolsas de monitoria, bolsas Pet e outros tipos de bolsa. Tal realidade talvez aconteça pelo fato desses tipos de bolsas possuírem uma maior oferta em universidades (públicas e/ou privadas) do que em faculdades privadas.

Posto isto, entendemos a partir dos resultados encontrados, que o FIES e o PROUNI contribuíram ao longo desses anos para a transformação do perfil socioeconômico dos estudantes do curso de Psicologia. A partir dos dados do perfil socioeconômico do ENADE 2015, pode-se afirmar que o curso de Psicologia já não figura mais como um curso hegemonicamente marcado pela presença de estudantes brancos, das classes sociais mais elitizadas e oriundos de escolas privadas. Pelo contrário, muitos estudantes de Psicologia são oriundos de famílias em que eles próprios são os primeiros de suas casas a vivenciarem a oportunidade de cursar o nível superior. Tal quadro reafirma a tese de uma possível via de popularização do curso de Psicologia a partir das políticas educacionais de ampliação do acesso ao ensino superior ao longo dos Governos do PT. Apesar do avanço é preciso ponderar acerca da permanência desse estudante no curso, bem como a qualidade da formação recebida.

\section{CONSIDERAÇÕES FINAIS}

A expansão do Ensino Superior no Brasil, quer seja no setor público por meio do REUNI, quer seja no setor privado por meio do PROUNI e do FIES, proporcionou um novo perfil ao estudante de Psicologia no Brasil: oriundo de famílias com baixa renda, com mães e pais com menor escolaridade, que estudaram em escolas públicas e representam os primeiros da família a cursarem um curso superior. Assim, percebe-se um maior alcance do ensino superior brasileiro entre os estudante oriundo das classes populares.

Entretanto, verifica-se que foi o setor privado o principal responsável por essa mudança de perfil nos cursos de graduação em Psicologia no Brasil. Historicamente, com o acesso concentrado entre aqueles mais favorecidos economicamente, hoje é o setor privado quem concentra maior número de estudantes de ensino superior das classes populares. Entende-se, portanto, a importância da criação de programas para o ensino superior (REUNI e PROUNI) ou que foram fortalecidos (FIES) nos Governos do PT (2003-2016), como importantes vetores de ampliação do acesso e de deselitização do perfil do estudante de graduação no cenário brasileiro.

Assim, alertamos que, apesar dos avanços, pondera-se acerca dos percalços, dos desafios e sobre as críticas quanto à forma como essas ferramentas de inclusão ganharam força a partir da lógica neoliberal e mercadológica em que está inserido o sistema educacional brasileiro. Desse modo, sugere-se a realização de novos estudos sobre o tema para aprofundar as análises sobre o impacto dessas políticas sob uma perspectiva mais qualitativa, a partir da avaliação da qualidade do ensino e das necessidades de implantação de políticas de integração e permanência dos estudantes a fim de tornar mais tangível o acesso de qualidade ao ensino superior para as camadas populares.

\section{REFERÊNCIAS}

Almeida, L. Marinho-Araujo, C. M., Amaral, A., \& Dias, D. (2012). Democratização do acesso e do sucesso no ensino superior: uma reflexão a partir das realidades de Portugal e do Brasil. Avaliação: Revista da Avaliação da Educação Superior (Campinas), 17(3), 899-920. https://doi.org/10.1590/S141440772012000300014.

Aprile, M. R., \& Barone, R. E. M. (2018). Educação superior: políticas públicas para inclusão social. Revista @ mbienteeducaşão, 2(1), 39-55.

Camilo, S. C. A. (2014). A reforma nas universidades federais brasileiras e a representação cultural do tempo histórico: uma análise do Programa de Apoio a Planos de Reestruturação e Expansão das Universidades Federais (REUNI)-2008-2012. [Apresentação de trabalho]. Anais do Décimo Quarto Encontro Regional de História: 1964-2014: 50 anos do Golpe Militar no Brasil. 
Catani, A. M., Hey, A. P., \& Gilioli, R. D. S. P. (2006). PROUNI: democratização do acesso às Instituições de Ensino Superior?. Educar em Revista, (28), 125-140. http://dx.doi.org/10.1590/S010440602006000200009.

Cavalcante, J. F. (2000). Educaşão superior: conceitos, definições e classificações. Instituto Nacional de Estudos e Pesquisas Educacionais. http://www.dominiopublico.gov.br/download/texto/me000095.pdf.

Costa, D. D., \& Ferreira, N. B. (2017). O PROUNI na educação superior brasileira: indicadores de acesso e permanência. Avaliação: Revista da Avaliação da Educação Superior (Campinas), 22(1), 141-163. https://doi.org/10.1590/s1414-40772017000100008.

Cruz, R. E. (2003). Banco Mundial e política educacional: cooperação ou expansão dos interesses do capital internacional? Educar em Revista, (22), 51-75. http:/ /dx.doi.org/10.1590/0104-4060.312.

Dominczak, P. R. R. (2015). Especulação e lucros fictícios: formas parasitárias da acumulação contemporânea. Argumentum, 7(2), 318-322. http://dx.doi.org/10.18315/argumentum.v7i2.11632.

Duquia, A. A., \& Borges, J. C. P. (2016). O reuni e o processo de empresarização da universidade federal de pelotas. [Apresentação de trabalho]. Anais Quarto Congresso Brasileiro e Estudos Organizacionais. Anais do Congresso Brasileiro de Estudos Organizacionais.

Felicetti, V. L., Cabrera, A. F., \& Costa-Morosini, M. (2014). Aluno ProUni: Impacto Na Instituição de Educação Superior e na Sociedade. Revista Iberoamericana de Educación Superior (RIES), 13(5), 21-39.

Felicetti, V. L., \& Cabrera, A. F. (2017). Resultados da Educação Superior: o ProUni em Foco. Avaliação: Revista da Avaliação da Educação Superior, 22(3), 871-893. https://doi.org/10.1590/s141440772017000300016.

Franco, A. D. P. (2008). Ensino Superior no Brasil: cenário, avanços e contradições. Jornal de políticas educacionais, 2(4), 53-63. http://dx.doi.org/10.5380/jpe.v2i4.15028.

Galzerano, L. S., \& Minto, L. W. (2018). Capital fictício e educação no Brasil: um estudo sobre a lógica contemporânea da privatização. Eccos Revista Cientifica, 47, 61-80. https://doi.org/10.5585/eccos.n47.10740.

Galzerano, L. S., \& Minto, L. W. (2019). Educação brasileira: a privatização sob a regência do capital fictício. [Apresentação de trabalho]. Anais do Sétimo Encontro Internacional de Política Social e Décimo Quarto Encontro Nacional de Política Social.

Ghelere, L. S. (2014). O perfil do bolsista prouni da UNESC: entre os limites e as possibilidades do ensino superior [Dissertação de Mestrado, Universidade do Extremo Sul Catarinense].

Giron, G. R. (2008). Políticas públicas, educação e neoliberalismo: o que isso tem a ver com cidadania? Revista de Educação PUC-Campinas, (24), 17-26.

Giron, G. R. (2014, 26 Maio). Reflexões sobre a história das políticas educacionais no Brasil. https://www.portaleducacao.com.br/conteudo/artigos/direito/reflexoes-sobre-a-historia-daspoliticas-educacionais-no-brasil/57059.

Ministério da Educação (2009). Programa de Apoio a Planos de Reestruturação e Expansão das Universidades Federais Reuni 2008 - Relatório de Primeiro Ano. Secretaria de Educação Superior, Diretoria de Desenvolvimento das Instituições Federais de Ensino Superior. http:/ / portal.mec.gov.br/index.php?option $=$ com_docman\&view $=$ download\&alias $=2069$-reunirelatorio-pdf\&Itemid $=30192$.

Ministério da educação (2012). Análise sobre a Expansão das Universidades Federais 2003 a 2012. Relatório da Comissão Constituída pela Portaria $n^{\circ}$ 126/2012. http:/ / portal.mec.gov.br/index.php?option $=$ com_docman\&view $=$ download\&alias $=12386$ analise-expansao-universidade-federais-2003-2012-pdf\&Itemid $=30192$.

Netto, J. P. (1999). A construção do projeto ético-político do Serviço Social. In Serviço Social e saúde: formação e trabalho profissional (pp. 141-160). Cortez.

Oliveira, Z. D. R. B. B., \& Carnielli, B. L. (2010). Fundo de Financiamento ao Estudante do Ensino Superior (FIES): visão dos estudantes. Jornal de Políticas Educacionais, 4(7), 35-40. http://dx.doi.org/10.5380/jpe.v4i7.21861.

Pereira, G. M. C., Castro, F. N., Lanza, L. N. M., \& Lanza, D. C. F. (2016). Panorama de oportunidades para os egressos do ensino superior no Brasil: o papel da inovação na criação de novos mercados de 
trabalho. Ensaio: Avaliação e Políticas Públicas em Educação, 24(90), 179-198. http://dx.doi.org/10.1590/S0104-40362016000100008.

Rawls, J. (1997). Uma Teoria da Justiça. Martins Fontes.

Ristoff, D. (2013). Perfil socioeconômico do estudante de graduação: uma análise de dois ciclos completos do Enade (2004 a 2009). Cadernos do Grupo Estratégico de Análise da Educação Superior no Brasil 2(4), 1-32.

Saviani, D. (1944). Escola e democracia: teorias da educação, curvatura da vara, onze teses sobre educação e política ( $9^{\mathrm{a}}$ ed.). Autores Associados.

Saviani, D. (1998). Da nova LDB ao novo Plano Nacional de Educação: por uma outra política educacional. Autores Associados.

Saviani, D., \& Duarte, N. (Orgs.). (2012). Pedagogia histórico-crítica e luta de classes na educação escolar. Autores Associados.

Silva, R. P. M. (1998). Teoria da justiça de John Rawls. Revista CEJ - Revista do Conselho da Justifa Federal, 138, 193-212.

Silva, J. S. D, \& Castro, A. M. D. A. (2014). Políticas de expansão para o ensino superior no contexto do REUNI: a implementação do programa na UFRN. HOLOS, 6, 206-224. https://doi.org/10.15628/holos.2014.2152.

Yamamoto, O. H., Seixas, P. S. \& Falcão, J. T. R. (2011). Quem é o estudante de psicologia do Brasil? Avaliaçao Psicologica: Interamerican Journal of Psychological Assessment, 10(3), 209-232.

Submetido: $22 / 07 / 2020$

Aprovado: 29/03/2021 